becomes a most unwelcome labour; while in the copy sent to us a list of the author's published writings is bound up between the text and the index-a most inconvenient and improper place for such an advertisement. We trust that no one will follow the example set either by the form or the position of this remarkable intercalation.

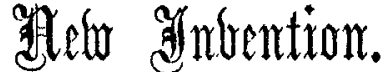

\section{A NEW INHALER FOR THE ADMINISTRATION OF ETHER.}

OF the two anxstbetics, chloroform and ether, the former is the one which in Scotland is almast universally preferred. By its use anæsthesia is easily produced, and that with no more apparatus than is afforded by a tolerably thick towel. Ether, on the other hand, is associated in men's minds with difficulty of administration, and with the employment of a more or less complicated and expensive apparatus, requiring the skill of a professed anesthetist, and it is accordingly shunned by all except a few, who, like myself, thoroughly believe in its superior safety over its younger rival. With the view of facilitating and rendering more general the administration of ether, I have for the past two years been endeavouring to devise an effective apparatus which should be not only safe in use and simole in action, but also economical of the anrsthesia, and I have at last succeeded in the construction of an inhaler possessing these qualifications, and, in addition, capable of producing anosthesia in a short space of time.

A reference to the accompanying woodcut will show that the inhaler is composed of two parts: the upper designed

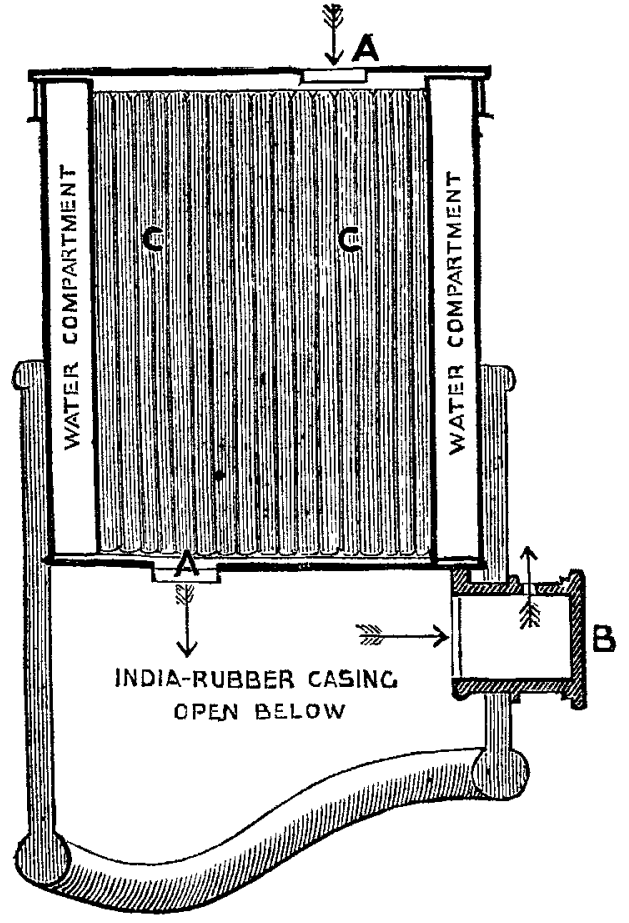

Vertical Section of Inhaler.

A, Respiratory valres. B, Expirstory valve. C, Convolutions of bandage

for the admission of air and for the reception and evaporation of ether, and the lower for application to the face of the patient. The upper or ether division is construc' ed of nickelplated metal, and consists (1) of a double-walled compartment adapted for containing a quantity of hot water to aid in the evap ration of ether ; (2) a central space (surrounded by the preceding water-jacket) completely filled by a metal frame, on which are stretched envvolutions of bandage, for the absorption of the anesthetic ; (3) a movable lid, fit'ed with an inspiratory valve; and (4) an immovable floor similarly provided. The lower or respiratory division of the inhaler is made of red rubher. Above, it is in close contact with, and encircles, the lower part of the ether division, while below, it is shaped fur adaptation to the face. It is furnished with an expiratory valve. From the above description, it will be gathered that inspiration opens the inspiratory valves, whereby the patient is made to breathe air heavily charged in its passage through the ether chamber with the vaponr of ether, while expiration closes them, the expired air escaping through the valve constructed for that purpose. It has always been my practice, previous to administering ether, to dull the sensibility of the respiratory mucous membrane by allowing the patient to inhale for about two minutes a few minims of chloroform dropped on a single fold of towel, and then to supply the ether by the apparatus in the following manner. The water-jacket having been filled with tolerably hot water, the lid of the inhaler is removed, and about two drachms of ether sprinkled on the bandage. The id is then replaced, and the apparatus closely fitted to the patient's face, great care being taken to apply it so exactly that on inspiration all air passes through the ether chamber before reaching the patient's Jungs. In abont half a minute a larger quantity of ether (half an ounce) is added, and similar quantities repeated, if necessary, until the patient is in a fit state for operation. Generally in from three to five minutes from the commencement of the inhala. tion of ether, anxsthesia is complete, and it can then be easily maintained by much smaller doses of the auresthetic. $I$ have used the inhaler in this way in many operations varying greatly in severity and duration, and it has always acted to my satisfaction. Certainly some patients were more difficult to manage than others; but on the whole I have had little trouble from what have been termed the inconveniences of ether, and none at all from the anxious symptoms so commonly observed during the administration of chloroform. In a few patients the ordinary face piece will prove somewhat large; and to obviate this inconvenience each inbaler will be provided with an additional face-piece rather smaller than that which is generally required. Towards the end of long operations the water in the jacket gets nearly, if not quite, cold; but this loss of temperature $I$ have not found to be of any practical moment, the warmth being chiefly neceseary at the commencement of anæstbesia, not after its establishment. Indeed, in very hot we ather in this country, or in warm climates, I believe that hot water might be dispensed with altogether.

In bringing my inhaler before the notice of the profession, I wish to direct attention to the following advantages which it poseesses:-1. Safety: The patient is made to breathe pure air mixed with the vapour of ether, and he never again inspires his own expired air. 2. Economy : He does not waste the anæsthetic by expiring through the bandage. Dissipation of ether is also controlled by the use of the lid, which acts in addition as a protection to the bandage from the wetting effects of antiseptic spray. 3. Simplicity : The inhaler is simple and self-acting, and the ether may be supplied witbont removing the apparatus from the patient's face. 4. Efficiency : Anæsthesia is easily and quickly induced, often before the surgeón has completed his preliminary an tiseptic precautions, and it is effectually maintained. The inhaler has been constructed by Messrs. Krohne and Sesemann, London, to whom my thanks are due for various suggestions and for assistance in points of practical detail.

P. BLAIKIE SMITH, M.D. Anæsthetist Royal Infirmary, Aberdeen.

\section{POOR-LAW MEDICAL OFFICERS' ASSOCIATION.}

To the Editor of THE LANCET.

SIR,-Will you permit me through your columna to announce that a general meeting of this Association will be held in Belfast during the meeting of the British Medical Association in that city, at a place and date hereafter to be decided on; and as it is my intention to comment on the deficiencies of Poor-law medical relief in the three kingdoms with the view to their mitigation or removal, I shall be obliged if Poor-law medical officers in $\mathbf{E}$.gland, dispensary officers in Ireland, and parochial medical officers in Scotland will forward to me a statement as to the grievances of which they have reason to complain, so that I might bring them before the meeting, $t$ specially instances where extra fees or superannuation allowances have been refused. I am, Sir, yours oberiently, Jos. Rogers, Chairman of the Poor-law Medical Officers' 33. Soho-square, July 2nd, $1884 . \quad$ Association. 